\title{
Maternal Health Care Seeking Behavior in Urban Area of Bangladesh: Does Migration Create Inequity?
}

\author{
Tasmiah Sad Sutopa* \\ Department of Statistics, Dhaka University, Dhaka-1000, Dhaka, Bangladesh
}

(Received: 27 March 2019 ; Accepted: 23 June 2019)

\begin{abstract}
The main aim of this paper is to find potential sources that affect maternal health care seeking behavior of women of urban areas in period around the birth of their children using data extracted from Bangladesh Urban Health Survey 2013. To examine the maternal health care seeking behavior among women, antenatal care, place of delivery and postnatal care are considered as dependent variables and several demographic and socio-economic factors are included as independent variable. The study reveals that the recent migrant women and slum dwellers have a tendency of being disadvantaged in context of maternal health care. There is still plenty of room to work on maternal health care among women in urban areas especially among recent migrants so that significant improvement can be initialized to achieve an equity in overall health care system in Bangladesh.
\end{abstract}

Keywords: Urban, Migration, Migrant, Antenatal Care, Place of Delivery, Postnatal Care.

\section{Introduction}

In Bangladesh, maternal mortality ratio (MMR) has been reduced significantly in last few years. According to Bangladesh Maternal Mortality and Health Care Survey 2016, MMR estimate is 196 maternal deaths per 100000 live births whereas in 2010 the estimate was 322 maternal deaths per 100000 live births ${ }^{1}$. Despite this sharp decline in MMR, considerable efforts must be employed to attain fifth millennium development goal (MDG 5) that is to improve maternal health ${ }^{2}$. Maternal and child mortality can be avoided successfully if prevention and management of maternal health complications in period around birth can be introduced through suitable life-saving interventions ${ }^{3}$.

Proper utilization of maternal health care services safeguards mothers from high rate of maternal and neonatal mortality. Maternal health care services encompass the services provided during pregnancy, childbirth and postpartum period ${ }^{4}$. Regular antenatal care (ANC), availability and accessibility of medical support during delivery (PoD) and effective postnatal care (PNC) can promote a safe motherhood with uneventful deliveries. Antenatal care expedites the detection and treatment of problems during pregnancy such as infections, hypertensive disease, and maternal anemia, and provides an important and timely opportunity to provide health information to women and their families ${ }^{5,6}$. Obstetric emergencies can be managed efficaciously throughdelivery care with medical facilities. Postpartum care is essential for detecting and treating infection and other conditions, including postpartum depression, and for providing advice on family planning 7. ANC, PoD and PNC covers the idea of continuum maternal health care which not only ensures the reduction in maternal morbidity and mortality but also guarantees decrease in neonatal death rate.

Bangladesh is experiencing a rapid urbanization process in last few decades. This urbanization process is being more stimulated by migration process ${ }^{8}$. It is observed that about two third of urban growth is due to migration from rural to urban area and for this reason internal migration is considered as primary factor of urbanization process that also provokes the heterogeneity of health care system ${ }^{9}$. A migrant is defined as a respondent whose place of birth is different from current place of residence or who said that they had not always lived at their current location which means he or she is from different city ${ }^{8}$. Because of scarcity of assets, this huge migrant population may not have access to health care system. As a result, the level of maternal health care utilization among migrants is relatively low that affects the overall urban maternal healthcare-seeking behavior of the country.

Several studies have been conducted to explore the demographic, socio-economic and health related variables affecting maternal health care utilization. Kusumaet. al. studied the factors that influence migrants in India to have access to maternal health care considering antenatal care and institutional delivery as dependent variables ${ }^{10}$. A cross sectional study of Badge et. al. revealed that there is a tendency of low utilization of ANC service and high proportion of home deliveries among migrant women in urban area ${ }^{11}$. Nabeenet. al. made an initiative through a study to identify potential factors that influence the ANC practice, institutional delivery and skilled birth assistant in Bangladesh $^{12}$. Soma and Bari employed negative binomial regression model to assess the factors impacting antenatal care visit of Bangladesh ${ }^{13}$.

The main aim of this study is to evaluate the factors that are associated with maternal health care among women of urban areas in Bangladesh by assessing potential sources that affect ANC, PoD and PNC of women using data extracted from Bangladesh Urban Health Survey 2013.

\section{Data and Variables}

To analyze the maternal health care practice among urban women of Bangladesh, the study used the data extracted from Bangladesh Urban Health Survey 2013. It is a secondary survey conducted to examine intra-urban differences in various health services and health outcomes in slum and nonslum areas. It was implemented through a collaborative effort

*Author for correspondence. e-mail: ts_sutopa@du.ac.bd 
of the National Institute of Population Research and Training (NIPORT), Measure Evaluation, University of North Carolina at Chapel Hill, USA, and ICDDR,B. It follows three stage stratified sampling. Three domains were considered to measure key indicators in this sampling design. These wereslum population in city corporations, non-slum population in city corporations and district municipalities and large towns with population over 45000 in 2011 census that is considered as other urban areas ${ }^{8}$.

Since main focus of this study was to identify the covariates that are associated with antenatal care, place of delivery and postnatal care, the outcome variables considered in this study were- antenatal care visits at least once during pregnancy (yes, no), place of delivery (home, hospital), postnatal care (yes, no). If respondent went for antenatal care during her pregnancy at least once, she was categorized as "yes", otherwise "no". Deliveries that took place in hospital or under medical support was identified as "hospital" category, otherwise "home". If anyone checked on mother's health after delivery, the respondent was reported as having postnatal care after delivery i.e. "yes" category otherwise respondent was categorized as "no" category.

On the basis of previous literature, the independent variables that were included in this study are- place of residence (slum, non-slum, other urban area), wealth quintile (poor, middle, rich), education of mother(no education, primary, secondary, higher), expose to media (unexposed, exposed), parity $(0,1$ $2,3+$ ), migration status (non-migrant, recent migrant, settled migrant), wanted pregnancy (yes, no), current working status of mother (yes, no), NGO membership (yes, no). All of these variables cannot be directly found from the survey. As for example, to explore migration status, respondents were categorized into three categories. The respondent whose current residence and birth place was same or who always lived in her current residence was categorized as nonmigrants and the rest are migrants. Among migrants, residents at current place for less than 5 years were considered as recent migrants, otherwise considered as settled migrants ${ }^{10}$. If mothers were associated with any one of the following non-governmental organizations (NGOs): Grameen Bank, Bangladesh Rural Advancement Committee (BRAC), Bangladesh Rural Development Board (BRDB), Association of Social Advancement (ASHA), Proshika or
Mother's club then they were considered as 'Yes' category, otherwise belong to "No" category of NGO member. The variable "exposed to media" was categorized as follows-if mother watched television or listened to radio or read newspaper was categorized as "exposed" to media, otherwise she was unexposed.

In this study, observations on the dependent variables were collected from the last birth of a mother born preceding 3 years of survey and 9014 observations were considered for analysis purpose. Bivariate analysis was performed to examine theunadjusted impact of selected independent variables in the study with ANC, PoD and PNC of urban women ${ }^{14}$. The variables which were found to be significant in bivariate analysis were included in regression analysis. As considered dependent variables in this study were binary in nature, binary logistic model has been employed to find adjusted effect of covariates on dependent variables ${ }^{15}, 16$. For computational purpose, SPSS v20 and R studio have been used.

\section{Result}

To examine how health care seeking behavior of mothers changed with place of residence and migration status, the percentage distribution of respondents were computed and the results are portrayed in Table 1 . Table 1 reveals that recent migrant women in slum area are deprived of receiving maternal health care.

Among recent migrants in slum area, about $68 \%$ women received antenatal care at least once during pregnancy, about $30 \%$ respondents delivered their babies at hospital and about $40 \%$ women went for postnatal care after delivery.Table 1 indicates that recent migrants are more at risk of being deprives of continuum maternal health care than the settled migrant and non-migrant in non-slum area. The percentage distribution of ANC receiver, institutional deliveries and PNC receiver are almost same for settled migrant and non-migrant in non-slum area. In rest of urban areas, maternal care seeking behavior is relatively high for recent migrants than the settled migrants and non-migrants. It has to be noted that, though ANC and PNC seeking behavior is comparatively high in three domains of urban area considered in this study, the proportion of women sought for institutional delivery is very alarmingly low.

Table 1. Percentage distribution of maternal health care services by place of residence and migration status

\begin{tabular}{|c|l|c|c|c|}
\hline Place of Residence & \multicolumn{1}{|c|}{ Migration Status } & $\begin{array}{c}\text { Received Antenatal } \\
\text { Care (\%) }\end{array}$ & $\begin{array}{c}\text { Child Delivered at } \\
\text { Hospital (\%) }\end{array}$ & $\begin{array}{c}\text { Received Postnatal } \\
\text { Care (\%) }\end{array}$ \\
\hline \multirow{3}{*}{ Slum } & Non-migrant & 74.5 & 45.0 & 47.2 \\
& Recent Migrant & $\mathbf{6 7 . 8}$ & $\mathbf{3 0 . 3}$ & $\mathbf{3 9 . 6}$ \\
& Settled Migrant & 71.1 & 38.8 & 43.6 \\
\hline \multirow{3}{*}{ Non-slum } & Non-migrant & 89.7 & 69.1 & 71.3 \\
& Recent Migrant & $\mathbf{8 4 . 6}$ & $\mathbf{5 8 . 1}$ & 67.1 \\
& Settled Migrant & 90.3 & 63.5 & $\mathbf{5 4 . 0}$ \\
\hline \multirow{3}{*}{ Rest Urban } & Non-migrant & $\mathbf{7 9 . 9}$ & 51.7 & 59.1 \\
& Recent Migrant & 83.6 & 54.2 & 54.2 \\
\hline
\end{tabular}


Results obtained from bivariate analysis were given in Table 2. Place of residence has significant effect on ANC, PoD and PNC. It is depicted from the Table 2 that women residing in slum area suffered from deprivation of antenatal care, institutional delivery and postnatal care than non-slum and other urban area. It is noted from the table that more than three-fourth $(76 \%)$ of recent migrants received antenatal care during pregnancy whereas around $80 \%$ of non-migrants and settled migrants utilized ANC service (79.9\% and $78.2 \%$ respectively). 43 out of 100 recent migrants went to hospital for delivering baby which is relatively lower than non-migrants and settled migrants (52.8\% and $48.0 \%$ respectively). Almost half of nonmigrant, recent migrant and settled migrants sought for postnatal care after delivery. Overall, the recent migrants are at risk of not going for maternal health care service.
From Table 2, it is evident that the inequity of receiving maternal health care services between the poor and the rich is very significant. Education of mother also has significant impact on the behavior of seeking maternal health care. The women attaining higher education are more likely to go for ANC, PoD and PNC than others $(98.0 \%, 85.6 \%$ and $87.1 \%$ respectively). Regular exposure to media makes the proportion of ANC receiver, delivery at hospital and PNC receiver relatively high $(81.1 \%, 52.3 \%$ and $56.1 \%$ respectively). Multiparous women (with 3 or more children) are more at risk of having inadequate maternal health care service. The women who did not intend to be pregnant at that time are reluctant to seek maternal health care services i.e. ANC, PoD and PNC $(70.3 \%, 43.1 \%$ and $47.7 \%$ respectively).

Table 2. Percentage distribution of maternal health care services by different demographic and socio-economic characteristics with p-values

\begin{tabular}{|c|c|c|c|c|c|c|}
\hline Covariates & $\begin{array}{c}\text { Received } \\
\text { Antenatal Care } \\
(\%)\end{array}$ & p-value & $\begin{array}{l}\text { Child Delivered } \\
\text { at Hospital }(\%)\end{array}$ & p-value & $\begin{array}{c}\text { Received } \\
\text { Postnatal Care } \\
(\%)\end{array}$ & p-value \\
\hline Place of Residence & & $<0.001$ & & $<0.001$ & & $<0.001$ \\
\hline Slum & 71.9 & & 39.7 & & 44.3 & \\
\hline Non-slum & 88.9 & & 65.1 & & 68.4 & \\
\hline Other Urban Area & 80.6 & & 51.8 & & 54.9 & \\
\hline Migration Status & & 0.003 & & $<0.001$ & & 0.002 \\
\hline Non-migrant & 79.9 & & 52.8 & & 55.1 & \\
\hline Recent Migrant & 76.0 & & 43.3 & & 50.4 & \\
\hline Settled Migrant & 78.2 & & 48.0 & & 52.2 & \\
\hline Wealth Quintile & & $<0.001$ & & $<0.001$ & & $<0.001$ \\
\hline Poor & 68.5 & & 34.8 & & 39.4 & \\
\hline Middle & 85.9 & & 54.7 & & 59.1 & \\
\hline Rich & 95.0 & & 77.2 & & 79.1 & \\
\hline Education of Mother & & $<0.001$ & & $<0.001$ & & $<0.001$ \\
\hline No education & 60.1 & & 29.4 & & 33.4 & \\
\hline Primary & 69.0 & & 35.1 & & 39.8 & \\
\hline Secondary & 46.5 & & 55.9 & & 59.8 & \\
\hline Higher & 98.0 & & 85.6 & & 87.1 & \\
\hline Expose to Media & & $<0.001$ & & $<0.001$ & & $<0.001$ \\
\hline Unexposed & 60.4 & & 28.3 & & 32.4 & \\
\hline Exposed & 81.1 & & 52.3 & & 56.1 & \\
\hline Parity & & $<0.001$ & & $<0.001$ & & $<0.001$ \\
\hline 0 & 84.7 & & 55.0 & & 59.0 & \\
\hline 1,2 & 77.7 & & 48.5 & & 51.9 & \\
\hline $3+$ & 59.1 & & 32.1 & & 37.1 & \\
\hline Wanted Pregnancy & & $<0.001$ & & $<0.001$ & & $<0.001$ \\
\hline Yes & 80.2 & & 50.6 & & 54.3 & \\
\hline No & 70.3 & & 43.1 & & 47.7 & \\
\hline
\end{tabular}


Table 2. Continued

\begin{tabular}{|c|c|c|c|c|c|c|}
\hline Covariates & $\begin{array}{c}\text { Received } \\
\text { Antenatal Care } \\
(\%)\end{array}$ & p-value & $\begin{array}{l}\text { Child Delivered } \\
\text { at Hospital }(\%)\end{array}$ & p-value & $\begin{array}{c}\text { Received } \\
\text { Postnatal Care } \\
(\%)\end{array}$ & \multirow{2}{*}{$\begin{array}{l}\text { p-value } \\
<0.001\end{array}$} \\
\hline \multicolumn{2}{|c|}{ Currently Working Status } & $<0.001$ & & $<0.001$ & & \\
\hline Yes & 30.0 & & 38.4 & & 43.7 & \\
\hline No & 19.6 & & 51.7 & & 55.3 & \\
\hline NGO Membershi & & 0.012 & & 0.003 & & 0.021 \\
\hline No & 20.9 & & 50.1 & & 53.8 & \\
\hline Yes & 23.9 & & 45.8 & & 50.5 & \\
\hline
\end{tabular}

Almost one-fifth of respondents who are unemployed sought for ANC (19.6\%). Additionally, more than half of the respondents who did not engage themselves job went for institutional delivery $(51.7 \%)$ and got PNC service $(55.3 \%)$.

Among the respondents who are NGO members, 23.9\% got ANC, $45.8 \%$ delivered their babies at hospital and $50.5 \%$ went for PNC.

The variables that are found to be significantly associated with ANC reception, place of delivery and PNC reception of women are incorporated in regression analysis as independent variables. As the dependent variables considered in this study are binary in nature, three separate binary logistic regression models are carried out. Table 3 is representing the adjusted effect of several covariates on
ANC reception during pregnancy, place of delivery and PNC reception after delivery.

Table 3 indicates that place of residence has significant effect on maternal health care service. The women living in slum have $16.1 \%$ lower odd of receiving ANC visit compared to women in non-slum area. Similarly, the women living in other urban area have $24.3 \%$ lower odd of receiving ANC visit compared to women in non-slum area. The women residing in other urban area have $19.3 \%$ lower odd of delivering her child in hospital than the women living in non-slum area. The women residing in other urban area have $21.5 \%$ lower odd of receiving PNC after delivery than the women living in non-slum area. The adjusted effect reveals that the women in other urban area are less likely to have access to maternal health care than the women in nonslum area.

Table 3. Estimated adjusted odds ratio (OR) and p-values obtained from logistic regression model for ANC, PoD and PNC

\begin{tabular}{|c|c|c|c|c|c|c|}
\hline \multirow[b]{3}{*}{ Covariates } & \multicolumn{6}{|c|}{ Response Variables } \\
\hline & \multicolumn{2}{|c|}{ Antenatal Care } & \multicolumn{2}{|c|}{ Place of Delivery } & \multicolumn{2}{|c|}{ Postnatal Care } \\
\hline & OR & p-value & OR & p-value & OR & p-value \\
\hline \multicolumn{7}{|l|}{ Place of Residence } \\
\hline Slum & 0.839 & 0.048 & 0.913 & 0.178 & 0.900 & 0.119 \\
\hline Non-slum & 1 & - & 1 & - & 1 & - \\
\hline \multicolumn{7}{|l|}{ Migration Status } \\
\hline Non-migrant & 1 & - & 1 & - & 1 & - \\
\hline Recent Migrant & 0.723 & $<0.001$ & 0.606 & $<0.001$ & 0.780 & $<0.001$ \\
\hline Settled Migrant & 1.034 & 0.606 & 0.901 & 0.054 & 0.982 & 0.732 \\
\hline \multicolumn{7}{|l|}{ Wealth Quintile } \\
\hline Poor & 1 & - & 1 & - & 1 & - \\
\hline No education & 1 & - & 1 & - & 1 & - \\
\hline Primary & 1.192 & 0.014 & 1.104 & 0.177 & 1.132 & 0.081 \\
\hline Secondary & 2.301 & $<0.001$ & 1.830 & $<0.001$ & 1.847 & $<0.001$ \\
\hline Higher & 9.781 & $<0.001$ & 5.686 & $<0.001$ & 5.555 & $<0.001$ \\
\hline \multicolumn{7}{|l|}{ Expose to Media } \\
\hline Unexposed & 1 & - & 1 & - & 1 & - \\
\hline Exposed & 1.442 & $<0.001$ & 1.383 & $<0.001$ & 1.340 & $<0.001$ \\
\hline
\end{tabular}


Table 3. Continued

\begin{tabular}{|c|c|c|c|c|c|c|}
\hline \multirow[b]{3}{*}{ Covariates } & \multicolumn{6}{|c|}{ Response Variables } \\
\hline & \multicolumn{2}{|c|}{ Antenatal Care } & \multicolumn{2}{|c|}{ Place of Delivery } & \multicolumn{2}{|c|}{ Postnatal Care } \\
\hline & OR & p-value & OR & p-value & OR & p-value \\
\hline \multicolumn{7}{|l|}{ Parity } \\
\hline 0 & 1 & - & 1 & - & 1 & - \\
\hline 1,2 & 0.648 & $<0.001$ & 0.759 & $<0.001$ & 0.758 & $<0.001$ \\
\hline $3+$ & 0.410 & $<0.001$ & 0.564 & $<0.001$ & 0.601 & $<0.001$ \\
\hline \multicolumn{7}{|l|}{ Wanted Pregnancy } \\
\hline Yes & 1.082 & 0.278 & 0.917 & 0.192 & 0.899 & 0.102 \\
\hline No & 1 & - & 1 & - & 1 & - \\
\hline \multicolumn{7}{|c|}{ Currently Working Status } \\
\hline Yes & 0.813 & 0.003 & 0.750 & $<0.001$ & 0.814 & 0.001 \\
\hline No & 1 & - & 1 & - & 1 & - \\
\hline \multicolumn{7}{|l|}{ NGO Membership } \\
\hline No & 1 & - & 1 & - & 1 & - \\
\hline Yes & 1.205 & 0.010 & 1.224 & 0.001 & 1.275 & $<0.001$ \\
\hline
\end{tabular}

Migration status also have significant adjusted impact on maternal health care service. It is exposed from the result that recent migrants have $27.7 \%$ lower odd of attaining ANC during pregnancy than the non-migrants. Again the recent migrants have $39.4 \%$ lower odd of having institutional delivery than non-migrants whereas settled migrants have $9.9 \%$ lower odd of delivering their baby in hospital than the non-migrants. Moreover, the recent migrants have $22.0 \%$ lower odd of attaining PNC after delivery than non-migrants. It is clear from the result that the recent migrants are more at risk of being deprived of maternal health care services than non-migrants and settled migrants.

From Table 3, it is notable that odds ratio increases as socioeconomic status gets higher which makes the fact lucid that socioeconomic inequality hinders women from accessing to health care.As odds ratio is increasing with the increase of level of education, it can be concluded that the uneducated women are less likely to receive ANC care compared to educated women and same pattern is followed for PoD and PNC reception. The mother exposed to media is 1.442 times as likely as to have ANC care during pregnancy than the mother unexposed to media. The mothers who keep in touch with electronic media are more likely to deliver their children in hospital and seek for postnatal care. Parity also has significant impact on maternal health care service. As the number of children increase, the odd of seeking ANC, institutional delivery and PNC decreases that indicates multiparous women are less likely to have maternal health care services. Working women are less likely to receive antenatal care compared to women who don't involve in any work $(\mathrm{OR}=0.813)$. Employed women are also less likely to deliver their babies in hospital and attain PNC after delivery $(\mathrm{OR}=0.750$ and $\mathrm{OR}=0.814$ respectively). Table 3 also summarizes that NGO members are more likely to have access to maternal health care disparities.

\section{Discussion}

Maternal health care services ensure successful health outcome for mother and newborn. A healthy mother leads to healthy families and societies that build up a strong health system and consequently a productive national economy. Though Bangladesh has experienced an immense progress in facilitating maternal health care services, still there is a long way to go ahead to fulfill the commitment of achieving MDG 5 indicated a substantial decrease in maternal mortality ratio (MMR) ${ }^{17}$. Due to extreme high rate of urbanization in last few decades, discrepancies in providing health care services in all classes of people in urban area have become an inevitable challenge for policy makers. Moreover, internal migration and tendency of rushing towards urban area for better life inflate this urbanization process and as a result subgroups of urban population are at a vulnerable position of being inaccessible to maternal health care system.

The main aim of this study is to find the factors that influence utilization of ANC during pregnancy, place of delivery and postnatal checkup after delivery in urban areas of Bangladesh. The study demonstrates that the women in slum area are at risk of receiving inadequate health care, which is due to large inequality in life style among people of slum, non-slum and other urban area.Despite high concentration of availability of maternal services in urban area, migrant people cannot access to them because of their mobilized change of residence, unstable economic condition, lack of adjustment in new environment and ignorance of health care provider. Consequently, recent migrants are in jeopardy of miss out of the continuum of health care services than the natives or settled migrants which is reported in this study resembling to previous studies $^{10,11}$. Poor women often lead a compromised living and working condition along with livelihood insecurity that compel them to deprive themselves from pursuing maternal health care.The findings of linkage between educational status and maternal health care in this study is strongly supported by previous literature ${ }^{12,13}$. Education makes 
women autonomous enough to stand for taking decisions regarding their health issues and knowledgeable about the benefits of health care. As a result, the proportion of maternal health care seeking behavior increases with the increment of education level ${ }^{10,13,18}$. The women who are in any touch of electronic media can get the information about the advantages of receiving antenatal care, institutional delivery and postnatal care that will motivate them to go for seeking maternal health care and it is conform to previous study ${ }^{19,20}$. The study explored that the women who are currently working are less likely to seek for maternal health care. It may happen because of lack of time due to balancing both professional and household responsibilities. NGOs serve a crucial role in rising the tendency of seeking for maternity care service among their members by providing knowledge related to health care service and implementing health care programs among their members ${ }^{21}$.

\section{Conclusion}

Despite overall progress, it is required to focus on urban areas of Bangladesh to make the health care services equitable to all classes of people. In this study, the barriers to access maternal health care system among urban women are identified.The slum dwellers and recent migrants should be more emphasized while implanting interventions regarding maternal health care. The knowledge regarding advantages of receiving maternal health care should be diffused among uneducated mothers. Adequate access to mass media may intensify the campaign on providing information related to maternal health care. Especially, poverty stricken mothers should be in center of attention of policy makers as they are still inaccessible to maternal health care system. It should be ensured that working women have enough facilities so that they can receive proper health care in the period of maternity. The NGOs should endeavor to facilitate the easy access to service providers for all women to increase the proportion of mothers having continuum maternal health care.The results obtained from this study may be affected by recall bias.

\section{Acknowledgement}

The author is thankful to National Institute of Population Research and Training (NIPORT), Bangladesh for providing Bangladesh Urban Health Survey 2013 data. The author is also grateful to Professor Dr. Wasimul Bari, Department of Statistics, University of Dhaka, for his valuable suggestions in various stages of this study.

\section{References}

1. National Institute of Population Research and Training (NIPORT), International Centre for Diarrhoeal Disease Research, Bangladesh (icddr,b), and MEASURE Evaluation. Bangladesh Maternal Mortality and Health Care Survey 2016: Preliminary Report. Dhaka, Bangladesh, and Chapel Hill, NC, USA: NIPORT, icddr,b, and MEASURE Evaluation, 2017.

2. National Institute of Population Research and Training (NIPORT), Mitra and Associates, and ICF International.
Bangladesh Demographic and Health Survey 2014.Dhaka,Bangladesh and Calverton, Maryland, USA: Mitra and Associates, and ICF International, 2016.

3. UNICEF. (n.d.). Maternal and newborn health. [online] Available https://www.unicef.org/health/index_maternalhealth.html [Accessed 21 Mar. 2019].

4. World Health Organization. (n.d.). Maternal health. [online] Available at: https://www.who.int/maternal-health/en/ [Accessed 21 Mar. 2019].

5. Carroli, G., J.Villar, G.Piaggio, D. Khan-Neelofur, M.Gülmezoglu, M.Mugford, P.Lumbiganon, U.Farnot, P.Bersgjø, and WHO Antenatal Care Trial Research Group, 2001. WHO systematic review of randomised controlled trials of routine antenatal care. The Lancet, 357(9268), 15651570 .

6. Carroli, G.,C. Rooney, and J.Villar, 2001. How effective is antenatal care in preventing maternal mortality and serious morbidity? An overview of the evidence. Paediatric and perinatal Epidemiology, 15, 1-42.

7. Warren C, P. Daly, L. Toure, P. Mongi. Postnatal care. In: Lawn J, Kerber K, editors. Opportunities for Africa's newborns : practical data, policy and programmatic support for newborn care in Africa. Geneva, Switzerland: WHO on behalf of The Partnership for Maternal, Newborn and Child Health; 2006, 79-90.

8. National Institute of Population Research and Training (NIPORT), International Centre for Diarrhoeal Disease Research, Bangladesh (icddr,b), and MEASURE Evaluation. Bangladesh Urban Health Survey 2013: Final Report. Dhaka, Bangladesh, and Chapel Hill, NC, USA: NIPORT, icddr,b, and MEASURE Evaluation, 2015.

9. Marshall, R. and S. Rahman, 2013. Internal migration in Bangladesh: character, drivers and policy issues. United Nations Development Programme (UNDP), New York.

10. Kusuma, Y.S., R.Kumari, and S.Kaushal, 2013. Migration and access to maternal healthcare: determinants of adequate antenatal care and institutional delivery among socioeconomically disadvantaged migrants in Delhi, India. Tropical Medicine \& International Health, 18(10), 1202-1210.

11. Badge, V.L., M. Pandey, Solanki, and M.J.Shinde, R.R., 2016. A cross-sectional study of migrant women with reference to their antenatal care services utilization and delivery practices in an urban slum of Mumbai. Journal of family medicine and primary care, 5(4), 759.

12. Nabeen, A.H.M., N.E.Jannat, M.A.S Akanda, 2018. Utilization of Antenatal Care, Skilled Birth Assistant and Institutional Delivery in Bangladesh. Dhaka University Journal of Science, 66(1), 21-27.

13. Sultana, N., W. Bari, 2017. Analyzing Overdispersed Antenatal Care Visits of Pregnant Women in Bangladesh: Negative Binomial Regression Model. Dhaka University Journal of Science, 65(2), 133-137.

14. Hogg, R.V.,J.McKean, and A.T. Craig, 2005. Introduction to mathematical statistics. Pearson Education.

15. McCullagh, P. \& J. Nelder, 1989. Generalized Linear Models. Second Edition. Chapman \&Hall .

16. Draper, N.R., H. Smith, 1966. Applied regression analysis. John Wiley and Sons, New York, London, Sydney. 
17. General Economics Division (GED), Planning Commission Government of the People's Republic of Bangladesh. Millennium Development Goals: Bangladesh Progress Report 2015, September, 2015.

18. Khanal, V., J.L.N.B. da Cruz, S.R. Mishra, R.Karkee, and A.H. Lee, 2015. Under-utilization of antenatal care services in Timor-Leste: results from Demographic and Health Survey 2009-2010. BMC pregnancy and childbirth, 15(1), 211.

19. Amrin, A., 2016. An Analysis of the Status of Antenatal Care in Bangladesh. International Journal of Science and Research Methodology, 5(2), 49-57.
20. Mahbub, M., M. Fatima-Tuz-Zahura, 2018. Factors Affecting Postnatal Care in Bangladesh: Clustered Data Analysis. Dhaka University Journal of Science, 66(1), 59-6.

21. Pulok, M.H., M.N.U. Sabah, J.Uddin, and U.Enemark, 2016. Progress in the utilization of antenatal and delivery care services in Bangladesh: where does the equity gap lie?. BMC pregnancy and childbirth, 16(1), 200. 
